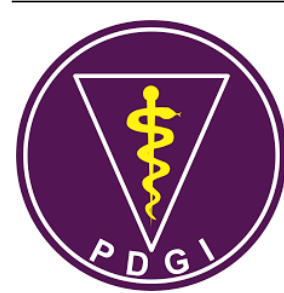

Indonesian Dental Association

Journal of Indonesian Dental Association

http://jurnal.pdgi.or.id/index.php/jida

ISSN: 2621-6183 (Print); ISSN: 2621-6175(Online)

Research Article

\title{
The Effect of Complete \\ Dentures on The Body Mass \\ Index of Elderly Patients
}

\author{
Andi Alifianti Puteri Asegaff ${ }^{1 \S}$, Nova Adrian² \\ 1 Undergraduate student, Faculty of Dentistry, Trisakti University, Indonesia \\ ${ }^{2}$ Department of Prosthodontics, Faculty of Dentistry, Trisakti University, Indonesia
}

Received date: December 13, 2018. Accepted date: March 5, 2019. Published date: April 30, 2019.

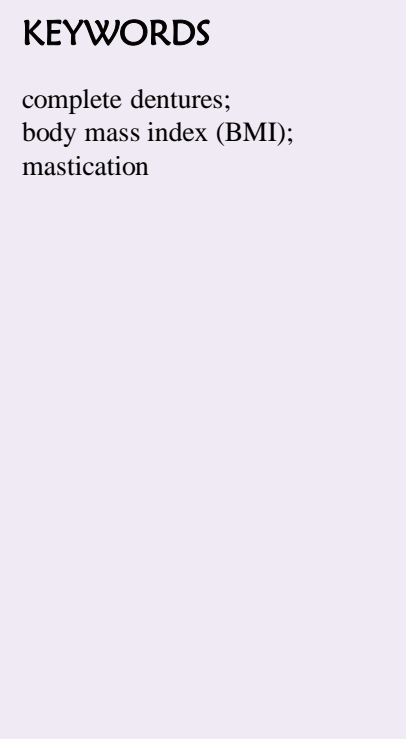

\begin{abstract}
Introduction: As people age, physical changes, such as complete tooth loss, can occur. The therapy for complete tooth loss is to wear complete dentures (CDs). However, this can affect patients' body mass index (BMI) and overall health, especially in patients who are elderly. $\mathrm{BMI}$ is an indicator that is often used to determine a person's nutritional status. Objective: The aim of this study was to analyze the effect of wearing a new set of full upper and lower dentures affects the BMI of elderly patients, one month after insertion at Dental Hospital of Dentistry Faculty, Trisakti University. Method: This was an observational analytic study with a cross-sectional design. The subjects of this study were 31 elderly patients (according to the World Health Organization [WHO] age classification). Result: Of the 31 elderly patients studied, 7 had an unstable or fluctuating BMI, 12 had a stable BMI from the beginning of CD insertion, 4 showed a consistent increase in BMI, and 2 showed a consistent decrease in BMI but remained in the normal BMI range. Using Spearman's rank correlation coefficient, the result was shown to be significant $(\mathrm{p}=0.00)$, which means there was a strong correlation between CD use and change in BMI (0.76-0.99). Conclusion: It can be concluded that elderly patients at Dental Hospital of Dentistry Faculty, Trisakti University who are wearing CDs encounter a significant change in BMI. Most of the subjects reached a normal BMI by one month after CD insertion, caused by an increased ability to masticate effectively.
\end{abstract}

\footnotetext{
${ }^{\S}$ Corresponding Author

E-mail address: ialifiantip@gmail.com (Asegaff AAP)
} 


\section{INTRODUCTION}

Aging is a biological, sociological, and economic phenomenon. ${ }^{1}$ This process is an absolute that occurs continuously to the extent that body function and capability are holistically affected by changes in anatomy, physiology, and biochemistry. An elderly person is characterized as someone who is 60 years or older; according to the World Health Organization (WHO), the elderly are classified into four groups: the middle-aged (45-59 years old), the elderly (60-74 years old), the old (75-90 years old), and the very old (over 90 years old). In Indonesia, specifically, article 1 of the Republic of Indonesia's Act No. 13 of 1998 classifies those aged 60 years and above as elderly. The elderly generally suffer from either poor nutrition or excessive nutrition. Those who reside in urban areas of Indonesian often face the following nutritional problems: $3.4 \%$ experience malnutrition, $28.3 \%$ are underweight, $6.7 \%$ are overweight, $3.4 \%$ experience obesity, and $42.2 \%$ have an ideal body weight. Previous data has suggested that the elderly commonly suffer from poor nutrition or are under weight. ${ }^{2}$

Millions of people around the world have lost all their teeth, and the prevalence of tooth loss increases with age. $^{3}$ Edentulism, or toothless, is a state in which the entire masticatory system is severely damaged, causing various problems with an individual's health as well as aesthetics concerns. The chewing ability of the elderly is significantly crippled when they lose their teeth, whether partially or entirely. As a result of tooth loss, elderly patients tend to prefer processed, cooked foods rather than fresh foods, to compensate for their weak mastication. They find it difficult to consume fruits, vegetables, and breads, leading to a nutritional imbalance in their diet. ${ }^{4}$

Demographically, the number of complete denture (CD) wearers is projected to be highest among elderly populations because their rehabilitation depends on the wearing of conventional CDs. Complete dentures are useful for restoring the function of missing teeth, even if they are not as comfortable as natural teeth. Those without teeth are reported to have different food choices from those with teeth. The denture wearer's diet usually consists of soft foods, limiting the variety of foods that can be consumed and increasing the risk of not fulfilling certain nutrient intake requirements; this can lead to oral diseases or even systemic diseases. ${ }^{5}$

In general, it appears that tooth loss and mastication are related to weight loss. While the relationship between dental conditions, chewing ability, and food choices has been explored from the point of view of public health and individual health, it is important to understand the specific relationship between tooth condition and weight in the context of the the health of the elderly. ${ }^{6}$ The mastication system is a functional unit composed of teeth, supporting structures, jaw bones, temporomandibular joints, and muscles. Mastication is an integral part of the process of swallowing and the early digestion of food, as well as gustatory perception. ${ }^{7}$

In some previous studies, no significant differences found related to body mass index (BMI) in the elderly after the insertion of CDs. In the first month, $31.7 \%$ of the subjects complained of discomfort with the prosthesis; however, after one month of treatment, almost half of the patients reported pain. ${ }^{8}$ Therefore, this study seeks to determine the effects of CD use upon the BMI of the elderly during the first month of treatment at Dental Hospital of Dentistry Faculty, Trisakti University, using scales, measuring tools, and questionnaires about mastication that were designed and tested for validity and reliability in 2012 by Dr. Isya Hanin. The aim of this study is to analyze whether new full upper and lower dentures affect the BMI of elderly patients after one month of insertion. The questionnaire is used only as a complement to the measurements, helping to determine whether there is a relationship between changes in BMI and the mastication of the subjects.

\section{MATERIAL AND METHODS}

This study outlines the effect of wearing CDs on the BMI of elderly patients after one month of insertion. The study was carried out at Dental Hospital of Dentistry Faculty, Trisakti University from August to December 2017 , with a total sample size of 31 elderly patients (as determined by the age classification defined by the WHO). The subjects wore a new full upper and lower CD and were examined during their first month wearing the CD. The number of samples for this study was obtained using a consecutive sampling method in which all subjects were treated as samples during the research, in accordance with the research inclusion criteria. This research is an observational analytic study with a crosssectional study design. All the subjects were informed of the purpose and objective of the study prior to filling out the informed consent sheet. This study has been approved by research ethics committee with registered number: 016/S1/KEPK/FKG/9/2017.

The next procedure was to fill in the personal data sheet and then having the BMI measured using weight scale $(\mathrm{kg})$ and height gauge $(\mathrm{m})$ under the assistance of researcher before the $\mathrm{CD}$ insertion was carried out for the first time on the subject by the clinic student operator of the Dental Hospital of Dentistry Faculty, Trisakti University. Body mass index obtained by calculating the body weight and height of the subject. To get the value, the researcher used WHO's formula which the weight divided with quadrate of the height. After one week the 
subjects had their weight re-measured using the same scale every week in one month after the first insertion, and they answered the questionnaires provided, which contained eight questions about the participants' mastication, by direct interview by the researcher. The body weight obtained at every scheduled visit within one month of $\mathrm{CD}$ insertion became the data that were processed and analyzed using the Statistical Program for Social Science (SPSS) program and tested using the Spearman data to track and closely examine whether were any changes in BMI during the one-month observation. Finally, scores resulting from the participants' questionnaires were summed up, analyzed, and processed using the same SPSS method; however, the Pearson's chi-squared test was also applied to help the researcher identify relationships between masticatory function and BMI change during the one-month observation.

\section{RESULT}

The following are the data from the research about the effect of wearing CDs on the BMI of elderly patients during one month after insertion at Dental Hospital of Dentistry Faculty, Trisakti University. The data were processed using SPSS 22.0 and are presented in Table 1 and Table 2.

\section{Sample Characteristics}

\section{Gender}

This research, conducted from August to December 2017, studied a total of 31 elderly subjects, including both men and women. Table 1 outlines the demographics of the study participants based on sex. It can be seen that, of the elderly wearers of CDs studied, 15 (48.4\%) were women and $16(51.6 \%)$ were men. As such, more slightly more men than women were included in this study.

Table 1. Characteristics of frequency distribution based on the sex of the CD-wearing subjects.

\begin{tabular}{ccc}
\hline Sex & Number & Percentage \% \\
\hline Male & 16 & 51.6 \\
Female & 15 & 48.4 \\
\hline
\end{tabular}

Ages

The age classification of research subjects was based on the WHO's definition, which classifies the elderly into four groups: the middle-aged (45-59 years old), the elderly (60-74 years old), the old (75-90 years old), and the very old (over 90 years old). The researcher chose to use the WHO classification due to its clarity and precision. See Table 2, below, for a breakdown of the ages of the study's participants.
Table 2. Characteristics of frequency distribution based on the age of the CD-wearing subjects.

\begin{tabular}{ccc}
\hline Age & Number & Percentage \% \\
\hline $\begin{array}{c}\text { Middle-Aged } \\
(45-59 \text { years old })\end{array}$ & 10 & 32.3 \\
$\quad \begin{array}{c}\text { Elderly } \\
(60-74 \text { years old })\end{array}$ & 19 & 61.3 \\
$\quad$ Old Elderly & 2 & 6.5 \\
$\left(\begin{array}{c}75-90 \text { years old }) \\
\text { Very Old } \\
(>90 \text { years old })\end{array}\right.$ & 0 & 0.0 \\
\hline
\end{tabular}

Based on the data in Table 2, above, the highest percentage is held by the population classed as "elderly" (i.e., aged 60-74 years), who account for $61.1 \%$ of the total number of subjects ( 19 of the 31 subjects). This is followed by middle-aged people (aged 45-59 years), of which there were $10(32.3 \%)$, and the very old (aged 7590 years), of which there were $2(6.5 \%)$. No very old subjects (aged 90+) participated in this study.

\section{BMI Assessment}

BMI assessment was based on the WHO classification, which divides body weight types into three groups: underweight (i.e., very thin, thin, and slightly thin), ideal body weight, and overweight (i.e., pre-obesity and obesity). For more details, see Table 3 below. The above data present the following findings: One (3.2\%) of the subjects is underweight and categorized as "slightly thin." Twenty-five $(80.6 \%)$ of the subjects fell within the normal weight range. Five subjects $(16.1 \%)$ were deemed as "overweight." Those within the "overweight" classification were further divided into two categories: "pre-obesity" (four subjects; 12.9\%) and "obesity" (one subject; $3.2 \%$ ).

\section{BMI Change Within The First Month}

Calculating the Spearman's rank correlation coefficient showed a significant change in the BMI of the elderly subjects during the first month of wearing CDs. In examining the correlation between the use of CDs and its effect on BMI, the researchers used SPSS 22.0 to conduct a Spearman test. The data used in this test was the control (i.e., BMI at the time of first insertion), followed by BMI at one week after insertion, two weeks after insertion, three weeks after insertion, and four weeks after insertion. Data interpretation allowed for a correlation analysis through Spearman's rank. For clarity, the interpretation was into three stages: the strength of the relationship between the variables, the nature and direction, and the significance of that relationship. 
Table 3. The BMI (WHO standard) of participants in the last control phase.

\begin{tabular}{ccccc}
\hline \multirow{2}{*}{ Classification } & \multicolumn{2}{c}{ BMI $(\mathrm{kg} / \mathrm{m} 2)$} & \multirow{2}{*}{ Total } & Percentage \% \\
\cline { 2 - 3 } & Principal cut-off points & Additional cut-off points & & 3.2 \\
Underweight & $<18.50$ & $<18.50$ & 1 & 0.0 \\
Very thin & $<16.00$ & $<16.00$ & 0 & 0.0 \\
Thin & $16.00-16.99$ & $16.00-16.99$ & 0 & 3.2 \\
Slightly thin & $17.00-18.49$ & $17.00-18.49$ & 1 & 80.6 \\
Normal & $18.50-24.99$ & $18.50-22.99$ & 25 & 0.0 \\
& & $23.00-24.99$ & & 16.1 \\
Overweight & $\geq 25.00$ & $\geq 25.00$ & 5 & 12.9 \\
Pre-Obesity & $25.00-29.99$ & $25.00-27.49$ & 4 & 0.0 \\
Obesity & $\geq 30.00$ & $27.50-29.99$ & & 3.2 \\
Obesity Class I & $30.00-39.99$ & $\geq 30.00$ & 1 & 3.2 \\
Obesity Class II & $35.00-39.99$ & $30.00-32.49$ & 1 & 0.0 \\
& & $32.50-34.99$ & & 0.0 \\
Obesity Class III & $\geq 40.00$ & $35.00-37.49$ & 0 & 0.0 \\
\hline
\end{tabular}

\section{Strength of the relationship between the variables}

In determining the strength of the relationships between the variables, we referred to the correlation coefficient value as the output of SPSS. This study's findings suggest a very strong relationship between $C D$ wears and the change of BMI which is 0.98.(i.e., a correlation of 0.76 to 0.99 ).

\section{Nature and direction of the relationship between the} variables

This study has two variables which is complete denture as $\mathrm{p} 1$ and the change of BMI of the subject as p2. If the numerical value determined in the results of the study is positive, the relationship between the two variables is linear. In other words, an increase in p1 implies an increase in p2. In the current study, a positive linear relationship was seen between CD use and BMI. As we can see, these two variables had a very strong relationship and positive linear that means p1 affected p2.

\section{Significance of the relationship between the variables}

Based on the data output, the significance value (Sig.) (two-tailed) was determined. If the Sig. is $<0.05$, that means there is a significant relationship between variables $\mathrm{p} 1$ and $\mathrm{p} 2$. In the current research, the Sig. was equal to 0.00 , demonstrating a significant relationship. This leads to the conclusion that the use of CDs on the elderly influences BMI in the first month at Dental Hospital of Dentistry Faculty, Trisakti University.

Relationship between The Use of CDs and Mastication Ability

In this test, the total score of the questionnaire was calculated using a Pearson test to obtain the correlation between changes in BMI and mastication data gathered through the questionnaire. This data used the same SPSS as was used to conduct Spearman's test, and the output was significant. Whether it is significant or not is determined in the same manner as it was for Spearman's test (the Sig. [two-tailed] was significant if $<0.05$ ). As a result of the Pearson test, a significant relationship between variables $\mathrm{p} 1$ and $\mathrm{p} 2$ was found.

\section{DISCUSSION}

As what previous chapters have shown, there is a significant change on body mass index (BMI) linked to the condition of the mastication ability of the elderly who wear complete denture (CD) for the first time at Dental Hospital of Dentistry Faculty, Trisakti University. In a previous study, Khan $\mathrm{M}$, et al, conducted a study on research subjects with new CD wearers in Punjab Dental 
Hospital Lahore, Pakistan. Their study was to assessed BMI and Nutritional Status by using questionnaire "Nutritional Health Checklist" on new CD wearers after one month denture therapy. Their study revealed that the subjects with normal BMI accounted for $58.8 \%$ and the overweight and the obese were $41.2 \%$ and statistically insignificant different was found between the nutritional status with age and BMI while significant relation was noted between the nutritional status and gender. ${ }^{9}$ The other side, this study was to revealed the effect of the CD itself on BMI of the elderly patients. This study shows that $3.2 \%$ of subjects are underweight, $80.6 \%$ are in normal BMI and overweight and obesity account for $16.1 \%$. The main result of this study was there is significant change in BMI on elderly patient who wear $\mathrm{CD}$ after one month therapy.

This study sought to analyze the effect of CD wear on the BMI of elderly patients treated with new complete upper and lower dentures. Weight $(\mathrm{kg})$ was measured before first insertion, as well as every week for the duration of one month after insertion, using the same scale, to two decimal places. At the same time those measurements were taken, the subjects answered questionnaires provided by the researcher, which contained eight questions about the participants' mastication, by direct interview by the researcher. The questionnaire was only included in the study as a complement to the measurements, but it helped to determine whether there was a relationship between the changes in BMI and mastication of the subjects. A significant change in BMI was linked to the mastication ability of the elderly participants who wore CDs for the first time. The result of this study was analyzed using SPSS 22.0 and two types of tests: Spearman's rank correlation coefficient and Pearson's chi-squared test, both of which showed a significant relationship between CD usage and BMI.

None of the subjects in this study were suffering from any systemic diseases, nor were they taking any ongoing medication. None of them suffered from a bent spine, either, means that the results of body weight and height measurements could be trusted. The data showed that the usage of CDs by the elderly has a positive impact on the patients' BMI, especially patients at Dental Hospital of Dentistry Faculty, Trisakti University. It can be implied that healthcare providers at Dental Hospital of Dentistry Faculty, Trisakti University are able to restore the mastication function of patients who have lost their teeth with CDs, which results in an improved BMI.

One's level of health is often reflected in BMI; as such, this study looked at the health of the elderly through the BMI in the beginning stages of CD usage. The data revealed that 3 participants experienced a decrease in BMI, 15 had a stable BMI, and 13 had an increased BMI one month after the control phase (i.e., one month after $\mathrm{CD}$ adoption). According to the results of Pearson's test - in which a significant relationship was seen between BMI and mastication questionnaire results - both a decrease in BMI and an increase in BMI was influenced by the mastication function of the research subjects observed during the control phases. Following the BMI classification of the WHO standard, this study found one person to have a BMI deficiency and five people to have an excessive BMI. Those with an excessive BMI were divided into "pre-obesity" and "obesity" groups; four people were categorized as "preobesity" and one person was categorized as "obesity." However, the use of CDs did not appear to influence BMI deficiency, as the subjects already had a belownormal BMI prior to wearing CDs. Similarly, four of the five subjects were considered to have an above-normal BMI before CD insertion. However, one participant did experience an increase in BMI to the pre-obesity level; this increase in BMI was seen at the second and third control week after wear of CDs.

Seven study participants had an unstable or fluctuating BMI, twelve had a BMI that was stable from the beginning of $\mathrm{CD}$ insertion, four showed a consistent increase in BMI, and two showed a consistent decline in BMI but did remain within the normal BMI range. This BMI change can be attributed to the convenience felt by the participants within the first month of wearing CDs; this tendency to adapt and feel comfortable with the condition is usually associated with a mastication ability. The specific focus of this study, however, was the change in the BMI of elderly patients during the first month of wearing CDs.

In carrying out any study, challenges are expected to occur. In this study, the main challenge that was faced was the issue of negotiating appointments for control visits with the research subjects. Each of them was often occupied with personal business, and as a consequence, they often could not make it to the scheduled control visit, which had been planned to allow for a one-week interval between each visit. For instance, some research subjects refused to have their body weight measured on the schedule planned for them, requesting that a different schedule be arranged. This affected the interval between the preceding and following visit, making it either less than a week or more than a week.

During the first to fourth control visit, the research subjects were given a questionnaire containing questions related to mastication ability when wearing their new CDs. Most of the research subjects did not complete the questionnaires themselves but were assisted by researchers, through an interview. In this study, all the tests performed produced outcomes that showed significant results. As such, it can be said that the 
mastication function that had been recovered by CD affected the BMI of the elderly patients at Dental Hospital of Dentistry Faculty, Trisakti University within the first month of wearing them.

\section{CONCLUSION}

This study showed that majority of the subjects who wore new upper and lower CDs for the first time had a normal BMI after one month and there was a significant difference in BMI occurred after CD's usage. The increased BMI in the subjects could be caused by the better ability of mastication.

\section{CONFLICT OF INTEREST}

Authors declare that there is no conflict of interest in this study.

\section{REFERENCES}

1. Karim HA. The elderly in Malaysia: demographic trends. Med J Malaysia. 1997;52(3):206.

2. Fatma. Gizi usia lanjut. Jakarta: Penerbit Erlangga. 2010:1.

3. Cousson PY, Bessadet M, Nicolas E, Veyrune JL,
Lesourd B, Lassauzay C. Nutritional status, dietary intake and oral quality of life in elderly complete denture wearers. Gerodontology. 2012;29(2):e68592.

4. Melia, Koesmaningati H, Dewi RS. Hubungan kehilangan gigi dan pemakaian gigi tiruan terhadap status nutrisi. Dep Prosthodont Fac Dent Univ Indones. 2014;3(2):5.

5. Alimin NH, Daharudin H. Nutrisi pada pengguna gigi tiruan penuh. Nutrition for the wearer of full denture. Dent. 2013;12(1):64-68.

6. Sheiham A, Steele JG, Marcenes W, Finch S, Walls AWG. The relationship between oral health status and Body Mass Index among older people: a national survey of older people in Great Britain. Br Dent J. 2002;192(12):703-6.

7. Shaikh S, Aziz F, Javed MU, Bin Saeed MH, Sharif M, Azad AA. Body Mass Index before and after provision of complete dentures. Pak Oral Dent J. 2012;32(2):335-9.

8. Heydecke G, Tedesco LA, Kowalski C, Inglehart MR. Complete dentures and oral health- related quality of life - Do coping styles matter? Community Dent Oral Epidemiol. 2004;32:297-306.

9. Khan M, Fatima A, Shah AA. Assesment of nutritional status one month after complete denture therapy. Pak J Med Sci. 2016;10(2):896-897. 